Volume 7

Issue 3 May

Article 10

May 1980

\title{
The Good Life: Who's Practicing Healthy Life-styles?
}

Ann S. Ford

Florida State University

W. Scott Ford

Florida State University

Follow this and additional works at: https://scholarworks.wmich.edu/jssw

Part of the Social Work Commons

\section{Recommended Citation}

Ford, Ann S. and Ford, W. Scott (1980) "The Good Life: Who's Practicing Healthy Life-styles?," The Journal of Sociology \& Social Welfare: Vol. 7 : Iss. 3 , Article 10.

Available at: https://scholarworks.wmich.edu/jssw/vol7/iss3/10

This Article is brought to you by the Western Michigan University School of Social Work. For more information, please contact wmu-scholarworks@wmich.edu.

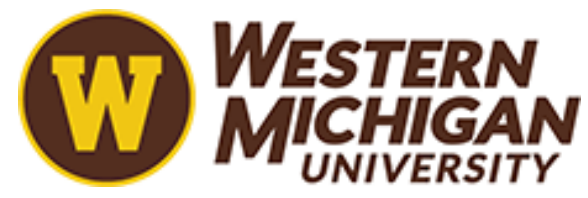




\title{
THE GOOD LIFE: WHO'S PRACTICING HEALTHY LIFE-STYLES? *
}

\author{
Ann S. Ford and W. Scott Ford \\ Florida State University
}

\begin{abstract}
"The greatest current potential for Improving the health of the American people is to be found in what they do or don't do to and for themselves."
\end{abstract}

Victor Fuchs, Who Shall Live?

With the birth of scientific medicine in the late $1800 \mathrm{~s}$, the responsibility for 'health' was increasingly removed from the individual and replaced by a dependence upon medical intervention and required public health measures. Individual responsibility was viewed largely in terms of assuring accessibility for the individual (and his/her family) to the professional health delivery system. The need for health care, therefore, was seen as episodic necessity --not as a continuing individual responsibility.

Not until the latter half of this century did we begin to see a resurgence of the role and responsibility of the individual to promote and maintain his/her own health. Whereas therapeutic medicine had solved many of the technical problems associated with established illness, much of the illness being treated was thought to be preventable, not by drugs or medical technology, but preventable by the adoption and maintenance of healthy life-styles. One indication of this renewed emphasis was the establishment, in 1971, of the President's Committee on Health Education; largely as a result of this Committee's report (President's Committee, 1973:25), the Bureau of Health Education was established (In 1974) within the Department of HEW's Center for Disease Control. A further expression of national intent in this area was the designation of public health education as one of the ten national health priorities in the National Health Planning and Resources Development Act of 1974

*Direct all communications to: Ann S. Ford: Department of Urban and Regional Planning; Plorida State University, Tallahassee, FL 32306. This is an expanded version of a paper presented to the Society for the Study of Social Problems, Boston, 1979. The data were collected pursuant to a contract with the office of Comprehensive Health Planning, Florida Department of Health and Rehabilitative Services, Tallahassee, Florida. 
(U.S. Laws, 88 Stat:2225). St111 another example of continuing interest in health promotion was the national symposium which took place in San Francisco in January of 1979; focusing on I1fe-styles and health, practitioners and scientists renewed their belief in the assumption of individual responsibility for good health.

Florida responded to the need for more effective consumer health education by approving the establishment of a system of regional Health Education Resource Centers (HERCs). Each Center would function as a coordinator of area programs, an innovator of new programs, and a clearinghouse for health education information and materials. The state pilot program was initiated in the 18 counties of northern Florida known as "the Panhandle"; the boundaries of the Florida Panhandle HERC were coterminious with those of the region's health systems agency.

\section{THE HOUSEHOLD HEALTH SURVEY}

Consumer health education can be defined as the process that informs, motivates, and helps people to adopt and maintain healthy practices and life-styles. Perhaps the most important question in health education today is: "How can we encourage/motivate people to lead healthier lives?" And, as a correlate to this query: "What kinds of people (in terms of attitudes, knowledge, behavior, demographic profile) currently do or do not practice 'healthy' life-styles?" The Florida Panhandle HERC decided to address this latter question; they contracted with the authors to conduct a health education needs assessment survey--selected results of which are reported in this article.

In the summer of 1978 , a household health survey was undertaken in the Florida Panhandle. 1 The household interview schedule

$1_{A}$ multi-stage area probability sample was employed in order to collect the household data. In order to reduce sampling error, in the first stage of sampling, the Panhandle counties were stratifled on the basis of education, income, size of largest town, and geographic location. The largest counties (population of 40,000 or more) were selected with certainty. Controlled probability selection was employed in order to insure geographic dispersion of counties. In the second stage of sampling, each county was divided into two strata - a c1ty directory stratum and an "area" stratum consisting of the proportion of the county not covered in the directory. The proportion of households falling within the city directory area varied across countles, but for all counties combined it represented approximately $75 \%$. Randomly selected areas on the average containing approximately 30 housing units, were 
used to collect the data was a comprehensive one; it was 28 pages In length, contained 24 different toplc sections, and ylelded up to 400 vartables for a given household depending on the number of family members and the number of applicable questions. The survey content was readily divided into four types of 1tems: healthrelated att1tudes and opinions; health knowledge; health-related behaviora; and questions which taken together could provide an abbrevlated health status profile. Toward the end of the schedule, a number of demograph1c/background variables were included. ${ }^{2}$

The objective of this paper 1s to explore the impact of selected variables upon healthy 11fe-styles. More specifically, we look at those individuals (primary household respondents) who engage in good eating hab1ts, exercise regularly for 1ts own sake, do not use tobacco, and use auto safety belts--and contrast them with their counterparts who do not routinely practice these positive health behaviors. Suggested reasons for Individuals' complalant or non-compliant behaviors are given by 1tems reflecting their demograhpic characteristics, predisposing att1tudes, and health-related knowledge.

In preliminary analyses, we examined a number of variables Individually and in combination which would best reflect eating habits, regular exercise, smoking behavior, and risk prevention. The vartables which emerged from these analyses are those which are respectively designated "SNACK3D," "SMOKE2A," "EXERCISE2," and "BELTS1." (These variables are described more fully in the note to Table 1.) Conceptually, these might be viewed as the major dependent varlables, reflecting respondents' compliant/ non-compliant behaviors; 1.e., "evidence" of a healthy/not healthy

taken to represent the nondirectory portions of countles. In all, Interviews were attempted at 604 eligible households; these attempts ylelded 321 fully completed interviews or a 53.5 percent response rate. Forty-nine percent of the respondent-households were located In SMSA count1es with populations of 50,000 or greater while 16 percent were located in "potential" SMS counties and 35 percent were in non-urban areas (1.e., rural or small town). For a detalled discussion of the sampling procedures, see Ford and Ford (1979).

2

Unlike the Hational Center for Health Statistics surveys, we did not attempt to acquire the same health status information for every household member. We were more concerned with a larger spectrum of 1ssues--particularly those concerning 11fe-style var1ables which could only be learned from the interviewees. The respondent sought was the adult "most knowledgeable" about the health of family members: this led to a much larger number of female primary respondents, [78\% (251) females and $22 \%$ (70) males]. 
1ife-style. These behaviors were chosen not only because of the number of relationships which appeared between them and other predisposing attitudes, characterisţics, and knowledge, but because of their current research interest. 3

\section{EMPIRICAL FINDINGS: CORRELATES OF POSITIVE LIFE-STYLES}

How prevalent were the selected behaviors in our study population? Fifty-nine percent (183) reported exercising everyday/ nearly everyday whlle $41 \%$ (128) did not; nearly half (46\%) of the 'exercisers' did so for "reasons of maintaining/regaining good health." The distribution of smokers $(39 \%, 121)$ ex-smokers (24\%, $74)$, and non-smokers $(37 \%, 116)$ was sufficiently variable as to make further analysis of smoking behavior worthwile. 4 Snacking Is often considered a national pastime; while the majority of our sample were no exception, $40 \%$ (122) reportedly did not routinely snack. Included within the $60 \%$ (187) who did snack everyday or nearly everyday, $12 \%$ (37) snacked only on nutritional foods, $18 \%$ (57) on both nutritional and 'Junk' foods, and $30 \%$ (93) on only 'junk' foods. By self-report the majority of our respondents $(60 \%, 186)$ did not use seat belts; an additional $18 \%$ (57) used them only "occasionally" while $22 \%$ (67) used them "frequently". Further users were further spectfied into "always use" (13\%, 40)

${ }^{3}$ Some recent articles related to nutrition and snacking behavior are (Abrams, 1978; Eshelman and McCloy, 1979; Fusillo and Beloian, 1977; Hansen and Wyse, 1979; Podell et al., 1978). Smoking and the correlates of this behavior have been subjected to extensive study in recent years; e.g., see (Croog and Richards, 1977; Eysenck, 1973; Foss, 1973; Jarvik et al., 1977; Lazarsfeld, 1973; Shewchuk, 1976; Thomas, 1973; U.S. Public Health Service, 1979; and West et al., 1977). Selected articles discussing frequency, type, and/or relationship of regular exercise to health include (Gallup OpInion Index, 1978; Heinzelmann and Bagley, 1970; Stalonas, Johnson, and Christ, 1978; and Young and Isma11, 1977). Use of seat belts and attempts to alter this behavior have been the subject of considerable research Including (Hart Research Associates, Inc., 1978; Helsing and Comstock, 1977; Neumann et al., 1974; Opinion Research Corporation, 1978; Reisinger and Williams, 1978; Robertson et a1., 1974; and Robertson, O'Neil and Wixon, 1972).

4 The percentage of smokers in our survey population was similar to that cited in a recent Surgeon General's report. While $39 \%$ of our respondents currently smoke, the Surgeon General report estimated that $38 \%$ of adult males and $30 \%$ of adult females smoked in 1978 (U.S. Public Health Service, 1979: viii). 
and "often use" $(9 \%, 27)$. Self-reported usage in our study was virtually identical to observed and self-reported usage found in several other large scale research projects. 5

Table 1 indicates the basic bivarlate relationships between each of the four "behavior" variables discussed above and selected other factors. Included in this Table are all those initially hypothesized relationships. Those relationships that were confirmed are designated by their levels of statistical significance.

In reviewing Table 1 , the strength of the demographic variables is apparent -- although given variables were not consistently related to all four behaviors. Based on this initial analysis, what characteristics were associated with the healthy practices? Not snacking (or nutritional snacking) was associated with each of the following attributes: older age, less education, few (or no) children, rural origin, and less tension. Non-smoking tended to be associated with older respondents, rural background, group membership, a higher than average body weight (by self-report), and low levels of daily tension. Non-smokers were able to name more of the seven warning signs of cancer than were smokers. While nonsmokers were less likely to feel threatened by heart attack/disease than were smokers, they were also less likely to cite 'not smoking' as a way to reduce chances of heart problems. The relationship between assessment of personal health vis-a-vis others and smoking behavior was unexpected; smokers tended to evaluate their own health as being better than familiar others more often than did non-smokers.

Engaging in regular exercise was associated with youth, higher levels of education, few (or no) children, average body weight, and low levels of tension. Exerclsers were more likely to cite 'proper exercise' as an important way to maintain 'good health'. They also perceived their own health as better than that of relevant others. Regular seat belt use was associated with higher education, employment, higher income, smaller family size, average body weight, and lower levels of tension. Belt users were more likely than non-belt users to assess their own health as better than others; they were also more knowledgeable about selected

5 Two studies prepared for the National Highway Traffic Safety Administration reported similar findings. Based on self-reported data, $25 \%$ of a selected sample of 2,016 adults frequently use seat belts (Hart Research Associates, Ine., 1978: 3). Based on observed usage, $14.1 \%$ of 68,679 adults were wearing seat belts at the time of observation (Opinion Research Corporation, 1978: 2,7). 
health matters such as knowledge of the basic four food groups and the seven warning signs of cancer.

Table 1. Bivariate Associations: Four Major Preventive Health Compliance Indicators by Demographic Characteristics, Predisposing Attitudes and Characteristics, and Knowledge

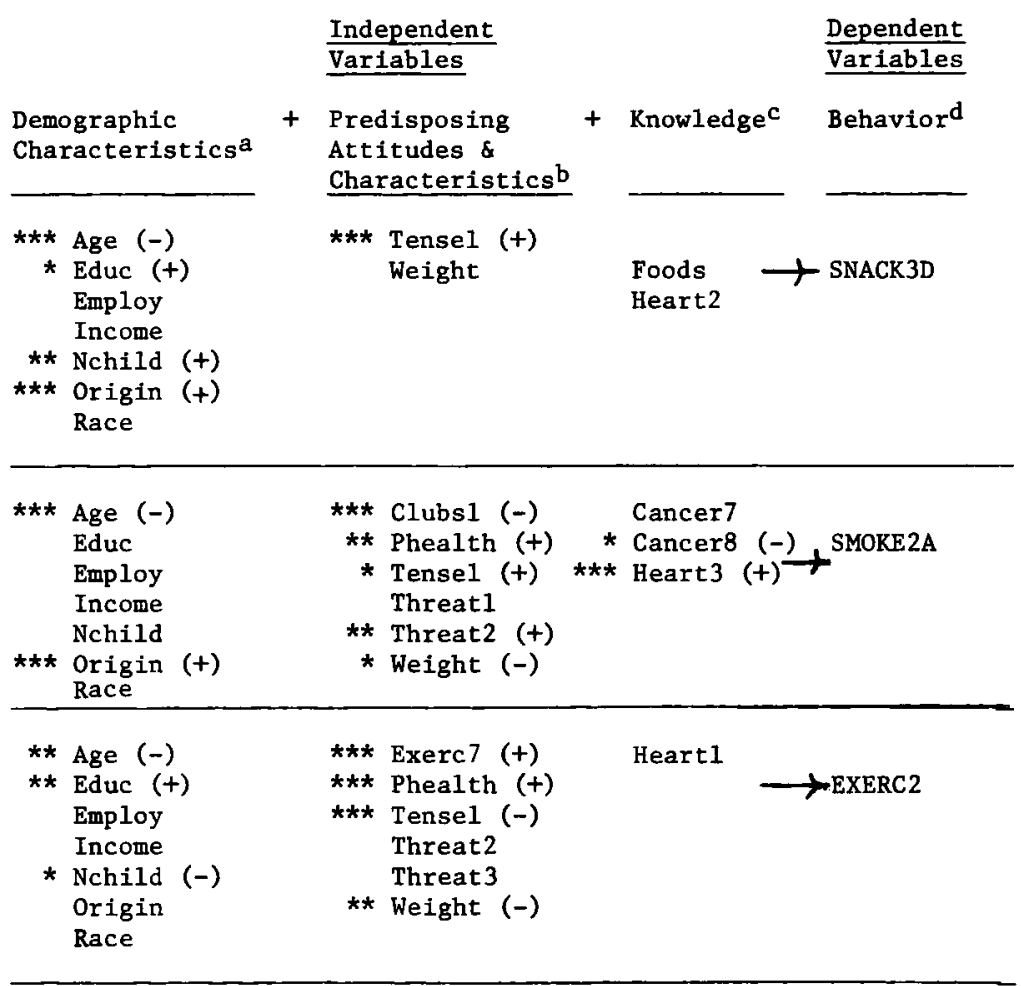

Table 1 continued....... 
Table 1 continued, .

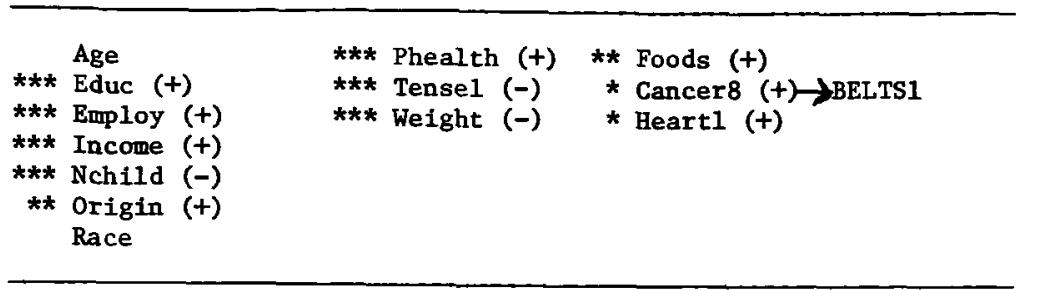

$$
\begin{aligned}
* & =.10 \geqslant p>.05, \text { tau } B / \operatorname{tau} C \\
* * & =.05 \geqslant p>.01 \text {, tau } B / \operatorname{tau} C \\
* * * & =.01 \geqslant p, \operatorname{tau} B / \operatorname{tau} C
\end{aligned}
$$

aDemographic characteristics reported are age (young = 18-44; old $=45+$ ), education (low $=$ less than high school; moderate $=$ high school graduate; high = post-secondary), employ (not employed outside the home; employed); income = less than $\$ 11,000$ per year; high $=\$ 11,000$ or more per year), nchild $(0=$ no children living in household; $1=1$ or 2 children living in household; $2=3$ or more children living in household), origin ( $1=\mathrm{rural} / \mathrm{smal1}$ town community-of-origin; 2 = small city/large city community-oforigin), and race ( 1 = White; 2 = Black).

${ }^{b}$ Predisposing attitudes and characteristics reported are clubsl (respondents were asked if they actively participate in any organizations, clubs, etc.), exerc7 (respondents were asked how important regular physical exercise is in keeping a person healthy), phealth (respondents were asked to evaluate the state of their own personal health compared to that of relevant others), tense1 (respondents were asked how often they feel tense and nervous), threat 1,2 , and 3 (respondents were asked to identify which of five major diseases they considered to be most threatening to their own health now or in the future; threatl = cancer; threat 2 = heart attack/heart disease; threat 3 = hypertension), and weight (respondents were asked if they consider themselves to be overweight and, if so, by how much).

$c_{\mathrm{Knowledge}}$ items reported are foods (respondents were asked to identify the four 'basic food groups'), cancer 7 and 8 (respondents were asked to name the seven warning signs of cancer; cancer7 $=$ named nagging cough as a sign of cancer; cancer $8=$ total number of cancer signs correctly named), heart 1,2, and 3 (respondents were asked to cite the ways an individual could reduce his/her chances of having a heart attack/heart disease; heart 1 = named 'proper exercise;' heart 2 = named 'proper diet;' heart 3 = named not smoking). 
Thus far we have identified the selected explanatory variables and presented an anlaysis of the major independent variables with the four health-related behavior variables. The statistically significant bivariate relationships were summarized. Throughout the following four sections, controls are introduced to further specify the nature of these primary relationships. The results are presented without extensive comment. Implications of these findings are reserved for the discussion section.

\section{Snacking Behavior (SNACK3D)}

SNACK 3D was used as an indicator of dietary habits (see Table AI). The bivariate relationship between tension (TENSE1) and snacking was hypothesized to be a negative one (hypA); i.e., those who snack nutritionally (or not at all) would be less likely to report frequent high levels of tension. This relationship was confirmed; it was strongest for the older respondents, the moderately and highly educated, those with high income, respondents in families with no children living at home, individuals with an urban community-of-origin, and for whites. "Positive" snacking behavior was also hypothesized to be negatively associated with overweight (hypB); i.e., those who nutritionally snack (or do not snack) would be less likely to be overweight. Upon analysis, this association was not statistically significant; however, when controls were introduced, the hypothesis was supported and found to be particularly strong for the following groups: older respondents, those with least education, the "unemployed," 6 individuals with 1 or 2 children in the home, respondents with a rural community-of-origin, and whites.

Knowing the basic four food groups (FOODS) was used as an indicator of nutritional knowledge; i.e., it was hypothesized that people who nutritionally snack (or do not snack) would be more likely to identify these groups correctly (hypC). This hypothesis

\footnotetext{
$\mathrm{d}_{\text {Behaviors include selected indicators for dietary habits (SNACK3D) }}$ = type of snacking behavior respondents engage in; no snacks; nutritional snacks; 'junk' food); exercise (EXERC2 = whether or not respondents report exercising every day or nearly every day), smoking behavior (SMOKE2A = whether respondents currently smoke, have smoked in the past but have stopped, or have never smoked), and seat belt usage (BELTS1 = if, and how often, respondents use seat belts).

6 "Unemployed" included women who were not employed outside the home as well as the retired and other unemployed.
} 
was also rejected; this rejection was particularly apparent for the older respondents, for those with no children living in the home, and for those with a rural community-of-origin. In concluding this section, we have found that the two preselected predisposing attitudes/ characteristics were useful indicators of 'good' snacking behavior; the knowledge indicators were not.

\section{Smok1ng Behavior (SMOKE2A)}

SMOKE2A was used as an Indicator of smoking behavior (see Table A2). The bivariate relationship between smoking and assessment of personal health compared to relevant others (PHEALTH) was hypothesized to be a positive one (hypE). Hypothesis $E$ was not supported in the bivariate nor was it supported when the controls were introduced. Interestingly, there was some suggestion that non-smokers were less likely than smokers to assess their own health as good compared to others; this was particularly true for respondents from small households, for those with a rural community-of-origin, and for Blacks. Another predisposing attitude/ characteristic was tension (TENSE1); frequent high levels of tension were hypothesized to be less 1ikely in non-smokers than in smokers (hypF). Moderate support was found for this hypothesis which was particularly strong for the young and for the Blacks.

Since non-smokers were practicing a "good" health behavior, we hypothesized that they would feel less threatened by diseases in which a direct linkage has been shown to smoking; e.g., cancer and heart attack/disease. Surprisingly, the bivariate between non-smoking and threat of cancer (hypG) was a relatively weak one but it was in the predicted negative direction. When controls were introduced, it (hypG) was confirmed for the old, the employed, the low income, and for those with a rural background. Further, it should be noted that hypG was soundly rejected for those respondents with an urgan community-of-origin; 1.e., non-smokers orlginally from urban areas were more likely than their smoker counterparts to feel threatened by cancer.

Hypothesis $\mathrm{H}$ explored the relationship between smoking and perceived threat of heart attack/disease. As predicted, nonsmokers cited fear of heart attack less often than did smokers; this was especially true for the older group, for those with less than a high school education, for the "unemployed," for the low income, for those with large families still at home, for those with rural backgrounds, and for Whites.

It was hypothesized that non-smokers would be more knowledgeable about the signs of cancer. CANCER7 and CANCER8 were used to assess this relationship. Both hypotheses (hypI and hypJ) were weakly supported. The assoctation between non-smoking 
and ability to name 'nagging cough' as a warning sign (hypI) was particularly strong within the older group and somewhat less so among Blacks and among the more highly educated group. It was expected that non-smokers would be able to name more of the seven warning signs of cancer than would smokers (hypJ). This finding was statistically significant for the older respondents, those with more years of education, the low income, those with large families still at home, individuals wth rural backgrounds, and among Blacks.

Non-swokers vere also expected to more often cite avoidance or cessation of swoking as a means of reducing their chances of heart attack/disease (hypK). This hypothesis, if supported, would have implied a direct relationship betreen knowledge and behavior. Rather surprisingly, hypothesis $R$ was soundly rejected $(-.000)$ ! Additionally, this negative association remained strong even when controls were introduced. Thus, one could conclude that smokers, as opposed to non-smokers, are more likely to see swoking as a direct threat to their health - and yet persist in the habit.

\section{Exercise (EXERC2)}

BXERC2 vas used as our indicator of daily/regular exercise (see Table 43 ). The bivariate relationship between exercise and an individual's attitude regarding the value of exercise to health (EXERC7) was hypothesized to be a positive one; i.e., those who regularly exercise would be more likely to feel that exercise was important for the mantenance of good health (hypL). This association recelved strong support. With the introduction of controls, the relationship was found to be especially strong across four jor groups - age, income, education, and race. Hypothesis $M$ suggested that dally exercise would be correlated with the perception of better health compared to relevant others. Again, the hypothesis was confired and was particularly strong for the older respondents, for those with the least education, for the lor income, and for both races.

Reported levels of daily tension were expected to be lower for those who exercise on a regular basis. The predicted negative relationship between tension and exercise was found to be a very strong one (hypN); it held for all age groups and both races but was strongest for the 10 incone and for those with a moderate amount of education.

Kany have speculated that the Incidence of heart attacks and hypertension night be reduced by regular exercise. One 
would, therefore, anticipate that those who exercise regularly would feel less threatened by these diseases. Rather unexpectedly, neither of these hypotheses (hyp0 and hypP) were supported, In fact, those with an urban community-of-origin were more likely to feel threatened and engage in regular exercise. The young, the high income, and those respondents with 1 or 2 children living at home were more likely to report regular exercise and to report a perceived personal threat of hypertension. Perhaps fear of these diseases (objectively justified or not) has been the impetus for establishing habits of regular exercise for these groups.

Finally, a knowledge 1tem (HEART1) was studied. It was expected that people who regularly exercise would be more likely to cite "proper exercise": as a means of reducing their chances of developing heart disease (hypQ). The bivariate analysis lent some weak support to this hypothesis. With controls, the relationship was found to be strong for the young, the employed, the low income, and for those with an urban community-of-origin.

In summary, the preselected predisposing attitudes/characteristics were found to be consistent correlates of regular exercise -- with tension and perception of the importance of exercise to health being the most useful indicators of compliance in this area. Those who regularly exercised were more likely to feel threatened by heart disease and/or hypertension. By exercising, perhaps they were deliberately acting to reduce this threat. The knowledge indicators were relatively weak predictors of exercise behavior.

Use of Seat Belts (BELTSI)

BELT1 was selected as the major indicator of risk prevention (see Table A4). The bivariate association between reported use of auto seat belts and one's personal health as compared to others was hypothesized to be a positive one (hypR). This hypothesis was strongly supported. It was even more strongly upheld among particular subgroups. When controls were introduced, the older respondents, those with less education, the "unemployed", those from lower income families, and respondents with no children living in the household were all groups for whom the relationship was especially strong. The association was only slightly stronger among those reared in the rural/small town settings than for those reared in urban areas; the same small difference was found between Blacks and Whites. 
A strong negative relationship was predicted to exist between use of seat belts and tension; 1.e., those persons who reported wearing seat belts would also report lower levels of daily tension (hyps). The data convincingly supported this hypothesis. This finding was strongest among younger respondents, the moderately well-educated, those with higher family incomes, and those having elther no children in the home or three or more. The strength and direction of this relationship was not altered by employment or community-of-origin.

It was hypothesized that people who routinely wear seat belts would be more knowledgeable in other health matters. Knowledge of the 'basic four' food groups (FOODS), the seven warning signs of cancer (CANCER8), and the relationship between exercise and reduction of heart disease were selected as measures of health knowledge. The relationship between routine seat belt use and the identification of the 'basic four' was confirmed (hypT). This relationship was particularly strong among the young, the highly educated, those without children in the household, those originally from rural areas, and Blacks. In the second knowldege item (CANCER8), it was hypothesized that routine users of seat belts would be more likely to correctly identify the seven warning signs of cancer (hypU). Whereas the relationship was in the predicted direction, it was not statistically significant. However, among White respondents and those reared in rural/small town settings, the positive relationship reached significance.

Finally, it was suggested that persons who regularly use seat belts would be more likely to designate "proper exercise" as a means of reducing their chances of developing heart attack/ disease (hypv). This relationship was supported at a moderately strong level. For Black respondents and for those living in households with one or two chlldren present, the relationship was particularly strong. When family income and community-oforigin were introduced as controls, respondents with low income and those with rural backgrounds also displayed strong support for the hypothesis.

As we found with the three previous health behaviors (snacking, smoking, and exercise), the best indicators of seat belt usage were classified as predisposing attitudes and characteristics; two particularly important indicators were a respondent's assessment of his/her own health relative to others and the daily level of tension which the respondent reported. The relationsh1p between general health knowledge and seat belt usage was stronger and more consistent than for the other three behaviors; 
yet, compared to the predisposing factors, knowledge level was a relatively poor correlate of such behavior.

\section{DISCUSSION}

Based on our analyses, what kinds of people (in terms of attitudes, knowledge, behavior, demographic characteristics) did or did not practice 'healthy' iife-styles? With regard to snacking, the stereotypes between snacking and tension and between snacking and overweight held for Whites but not for Blacks. older people who snacked nutritionally (or not at all) were less likely to be overweight than older people who snacked indiscriminately; however, snacking behavior in younger people did not have the same predictable effect on weight. The well-educated were more 11kely to report snacking associated with high levels of tension than were the less well-educated. Knowledge of the 'basic four' was essentially unrelated to snacking behavior. The non-nutritional snackers were somewhat likely to identify 'proper diet' as a way to reduce chances of a heart attack/disease -exhibiting behavior in direct contradiction to their knowledge of 'appropriate' behavior.

Smoking is generally acknowledged as detrimental to health; therefore, it was interesting to find that smokers were somewhat more likely than non-smokers to assess their own health as being better than that of relevant others. Perhaps smoking was a risk which only those who percelved themselves as "healthy" were willing to take! That smokers were 'consclous risk-takers' was further suggested by the findings that smokers, more of ten than non-smokers, cited 'non smoking' as a way to reduce chances of heart disease -- another example of acting in contradiction to one's 'knowledge' of what was 'appropriate' behavior. Although the relationship between cancer and smoking has been the subject of controversy, smokers were only slightly more likely to perceive cancer as a threat than were non-smokers. This was probably because we all fear cancer, but one would have expected smokers to feel this threat more acutely than would non-smokers. Smokers were appreciably more likely than non-smokers to fear heart attacks/disease. This was particularly true of the older group; older non-smokers were less likely to fear heart disease than their age peers who smoked.

Regular exercise is associated in most people's minds with general physical fitness. People who exercised every day were more likely to value their own health and to rate their own health as being better than most. That we found this association was not surprising; however, the specifications of the 
primary relationship was of particular interest; the old who exercised assessed their health as being better than others much more of ten did the old who did not exercise. Similar relationships were found for the less well-educated as compared to the well-educated and for the low income relative to the high income. The old, the low income, the less well-educated are prime targets of the health educator. They are of ten cited for non-compliance. Here we see that, when (and if) members of these groups are "compliant," they become committed to their behavior. This commitment to exercise was also evident in the specification of the initial relationship between exercise and attitude toward exercise (EXERC7); people who exercise saw exercise as instrumental in keeping them healthy -- a relationship which was as strong for the low income as for the high income, as strong for the Blacks as for the Whites, as strong for the young as for the old, and as strong for the less well-educated as for the welleducated. Thus, regular exercise was viewed as an instrumental behavior; if one exercised, one would be healthy. Release of tension is often seen as a benefit of regular exercise; our data confirmed a negative relationship between tension and exercise. This was particularly true for the low income and held across age, education, and racial groups.

Similiar to daily exercise, the routine use of auto safety belts requires a continuing and active commitment to the maintenance of good health -- in this instance, by reducing injury from accidents. Unlike smokers ("the conscious risk-takers"), seat belt users were more consistently found to hold health-related attitudes which confirmed our original expectations. Additionally, among belt wearers, the relationship between using belts and health-related knowledge items was more consistently in the direction expected. Particularly striking was the strong association between seat belt use and a positive assessment of one's own health relative to others. Perhaps "buckling up" assured the wearer of keeping this positive assessment a realistic one, enchancing the likelihood of maintaining good health. Correspondingly, seat belt users were less likely than non-users to report frequent high levels of daily tension. These findings suggested that the seat belt wearer may be an individual with a consistent commitment to the practice of good health behaviors.

\section{FUTURE DIRECTIONS}

We have identified some of the characteristics of those who live (or do not) live the "good" life. Knowledge of these 
characteristics should bring us somewhat closer to answering the important question: "How can we encourage/motivate people to lead healthier lives?" Our initial hope was to construct a dichotomy of those who practice good health behaviors and those who do not. Ideally, we had sought to identify attributes of these groups that would be consistently related to all four types of behavior. Although we have not fully succeeded, we have uncovered a number of interesting relationships worthy of further consideration.

Holding each dependent behavior constant, we checked for an association ${ }^{7}$ between each of the other three dependent variables. For example, among non-snackers, there was a significant negative association $(-.04)$ between smoking and seat belt use; for snackers, the positive association between exercise and seat belt use was also significant $(+.03)$. For non-smokers, important relationships existed between exercise and belt use $(+.04)$ and between belt use and snacking $(-.04)$. Looking only at people who had "quit the habit," we found a significant negative relationship between belt use and snacking $(-.01)$. Next, we looked at current smokers expecting to also find an association between some of the other three behaviors; however, for these respondents, there were no significant associations between any of the other health behaviors!

Continuing our analyses, we turned to the exercisers. Again, there was a moderate association between several of the other health behaviors; in this case, significant relationships existed between smoking and belt use $(-.07)$ and between belt use and snacking $(-.10)$. For the non-exercisers, there was a strong negative relationship between wearing seat belts and snacking; i.e., significant at the -.01 level.

Finally, we looked at seat belt use. For belt users, we found a moderately significant relationship between smoking and snacking $(+.07)$ and between exercise and snacking (+.06) The latter association suggested that those who wear seat belts might not be the "behavior consistents" we had initially concluded; i.e., if individuals regularly. used seat belts, there was a fair likelihood that, if they exercised, they would also snack indiscriminately. In addition to this anomalous finding, we discorered a second "behavior inconsistent" group: those individuals who did not use seat belts. For this group of respondents, there were no significant associations between any of the other three health behaviors.

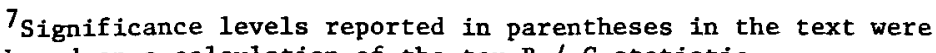
based on a calculation of the tau B / C statistic. 
The conclusions we should derive from these findings are not yet apparent. We could tentatively suggest that it is possible to identify two groups: "behavior consistents" and behavior inconsistents." Identification of the major similiarities and/or dissimillarities both within and between these two groups could help us better understand what is associated with the adoption and practice of healthy life-styles.

\section{REFERENCES}

Abrams, I. J.

1978 "Determining Consumer Demand and Marketing Opportunities for Nutritional Products." Food Technology: $79-85$.

Becker, Marshal1 $\mathrm{H}$. and Lois A. Maiman

1975 "Sociobehavioral Determinants of Compliance with Health and Medical Care Recommendations." Medical Care 13: 10-24.

Berkanovic, Emil

1976 "Behavioral Science and Prevention." Preventive Medicine 5: 92-105.

Croog, Sydney H. and Nancy P. Richards

1977 "Health Beliefs and Smoking Patterns in Heart Patients and Their Wives: A Longltudinal Study." American Journal of Public Health 67: 921-930.

Eshelman, Ruth E, and Katherine McCloy

1979 "The Changing Face of Community Nutrition." Family and Community Health" The Journal of Health Promotion and Maintenance $1: 1-6$.

Eysenck, H. 3 .

1973 "Personality and the Maintenance of the Smoking Habit." Pp. 113-146 in William L. Dunn, Jr. (ed.), Smoking Behavior: Motives and Incentives. Washington, D. C.: V. H. Winston and Sons.

Ford, W. Scott and Ann S. Ford

1979 Health Education Assessment Survey: The Florida Panhandle. Atlanta, Georgia: Bureau of Health Education, U. S. Department of Health, Education and Welfare. 
Foss, Robert

1973 "Personality, Social Influence and Cigarette Smoking. Journal of Health and Social Behavior 14: 279-286.

Fuchs, Victor R.

1974 Who Shall Live? New York: Basic Books.

Fusillo, Alice E. and Arletta M. Beloian

1977 "Consumer Nutrition Knowledge and Self Reported Food Shopping Behavior." American Journal of Public Health $67: 846-850$.

Gallup Opinion Index

1978 "Nearly Half of Americans Now Exercising Daily: 24 Percent Are Joggers." Gallup Opinion Index: Report number 151 .

Haggerty, Robert J.

1977 "Changing Lifestyles To Improve Health." Preventive Medicine 6: 276-289.

Hansen, R. Gaurth and Bonita W. Wyse

1979 "Planning for the Inevitable: Snack Foods in the Diet." Family and Community Health: The Journal of Health Promotion and Maintenance 1: 31-39.

Hart Research Associates, Inc.

1978 Public Attitudes Toward Passive Restraint Systems: Summary Report. Washington, D. C.: National Highway Traffic Safety Administration, U. S. Department of Transportation.

Heinzelman, Fred and Richard W. Bagley

1970 "Response to Physical Activity Programs and Their Effects on Health Behavior." Public Health Reports 85: $905-911$.

Helsing, Knud J, and George W. Comstock

1977 "What Kinds of People Do Not Use Seat Belts." American Journal of Public Health 67: 1043-1050.

Jarvik, Murray E., Joseph W. Cullen, Ellen R. Gritz, Thomas M. Vogt and Louis Jolyon West (eds.)

1977 "Research on Smoking Behavior. NIDA Research Monograph 17. Washington, D.C.: U. S. Government Printing office. 
Lazarsfeld, P. F.

1973 "The Social Sciences and The Smoking Problem."

Pp. 283-286 in William L. Dunn, Jr. (ed.), Smoking

Behavior: Motives and Incentives. Washington, D. C.: V. H. Winston and Sons.

Neumann, Charlotte G., Alfred K. Neumann, Margaret E. Cockrell and Sheila Banani

1974 "Factors Associated With Child Use of Automobile Restraining Devices." American Journal of Diseases of Children 128: 469-474.

Opinion Research Corporation

1978 Safety Belt Usage: Survey of Cars in the Traffic

Population (November 1977 - June 1978). Washington,

D. C.: National Highway Traffic Safety Administration,

U. S. Department of Transportation.

Podell, Richard N., Kathryn Keller, Michael N. Mulvihill, Gary Berger and Donald Kent

1978 "Evaluation of the Effectiveness of a High School Course in Cardiovascular Nutrition." American Journal of Public Health 68: 573-576.

President's Committee on Health Education

1973 Report. Washington, D. C.: U. S. Government Printing office.

Reisinger, Keith S, and Allan F. Williams

1978 "Evaluation of Programs Designed to Increase Protection of Infants in Cars." Pediatrics 62: 280-287.

Robertson, Leon S., Albert B. Kelley, Brian O'Neill, Charles W. Wixom, Richard $S$. Eiswirth and William Haddon

1974 "A Controlled Study of the Effect of Television Messages on Safety Belt Use." American Journal of Public Health 64: 1071-1080.

Robertson, Leon S., Brian O'Neill and Charles Wixom

1972 "Factors Associated with Observed Safety Belt Use." Journal of Health and Social Behavior 13: 18-24.

Schewchuk, L. A.

1976 "Smoking Cessation Programs of the American Health Foundation." Preventive Medicine 5: 454-474.

Somers, Anne R. (ed.)

1976 Promoting Health. Germantown, Maryland: Aspen Systems Corporation. 
Stalonas, Peter M., William G. Johnson and Maryann Christ

1978 "Behavior Modification for Obesity: The Evaluation of Exercise, Contingency Management, and Program Adherence." Journal of Consulting and Clinical Psychology 46: 463-469.

Thomas, C. B.

1973 "The Relationship of Smoking and Habits of Nervous Tension." Pp. 157-170 in William L. Dunn, Jr. (ed.), Smoking Behavior: Motives and Incentives. Washington, D. C.: V. H. Winston and Sons.

U. S. Laws, Statutes

1974 "National Health Planning and Resources Development Act of 1974." Public Law 93-641. 88 STAT. 2225.

U. S. Public Health Service

1979 Smoking and Health: A Report of the Surgeon General. Washington, D. C.: U. S. Government Printing Office.

West, Dee W., Saxon Graham, Mya Swanson and Gregg Wilkinson 1977 "Five Year Follow-Up of a Smoking Withdrawal Clinic Population." American Journal of Public Health 67: 536-544.

Young, R. John and A. H. Ismail

1977 "Comparison of Selected Physiological and Personality Variables in Regular and Nonregular Adult Male Exercisers." The Research Quarterly 48: 617-622. 
Table Al. Snacking Behavior Controlling For Major Demographic Characteristics

\section{Snacking Behavior (SNACK3D)}

Hypothesis A: Nutritional snacking (or not snacking) is negatively assoclated with tension.

I. Leve1 of Da1ly Tension (TENSE1)

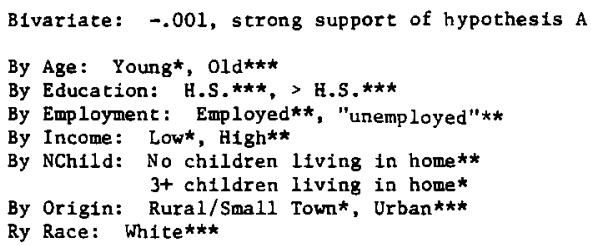

Hypothesis B: Nutritfonal snacking (or not snacking) is negatively associated with overweight.

II. Weight (WEIGHT)

Hypothesis B supported:

Hypothesis B rejected:
BIvariate: -N.S., direction suggests weak support of hypothesis B

By Age: $01 d * \star$

By Education: < H.S.*

By Employment: "unemployed"*

By NChild: 1 or 2 children living in home*

By Origin: Rural/Small Town*

By Race: White**

No significant relationships

Hypothesis C: People who regularly snack on nutritional foods (or do not snack) are more likely to know the four major food groups.

III. Basic Four Food Groups (FoODS) Bivarlate: -N.S., direction suggests weak rejection of hypothesis Hypothesis $C$ supported: No significant relationships Hypothesis $C$ rejected:

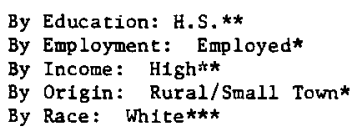

Hypothesis D: People who regularly snack on nutritional foods (or do not snack) are more likely to Identify proper diet as a way to reduce their chances of heart attack/diseases.

IV. Heart Problem \& Diet (HEART2) Bivariate: - N.S., direction suggests weak rejection of hypothesis D Hypothesis D supported: No significant relationships

Hypothesis D rejected: By Age: 01d** By NChild: No children living in home** By Origin: Rural/Small Town

* .10 $\geqslant p>05$, tau B/tau $C$

$\star \star .05 \geqslant p>01$, tau $B / \operatorname{tau} C$

$\star \star \star .01 \geqslant p$, tau $B /$ tau $C$ 
Table A2. Smoking Behavior Controlling for Mafor Demographic Characteristics

\section{Smoking Behavior (SMOKE2A)}

Hypothesis E: Non-smokers are more likely to assess their own personal health as being better than relevant ochers.

I. Personal Health Cowpared to Others (PEBALTH)

Bfvarlate: $-N . S$. , direction suggests weak refection of hypothesis $\mathrm{E}$

Hypothesis E supported:

No significant relationghips

Eypothesis E rejecred:

By NCh1ld: No children living in home*

By OrIgin: Rural/Small Town*

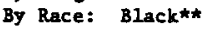

Hypothesis F: Non-amokers are less likely to report high levels of tension.

II. Level of Daily Tension (TBMSEI)

B1varlate: $\quad .08$, moderate support of hypothesis $F$

Bypothes1s F supported:

By Age: Young*

By Race: Black**

Hypothesis $F$ rejected:

No significant relationehips

Hypothes1s G: Non-swokers are less likely to percelve cancer as a personal chreat now or in the future.

III. Cancer as Personal Threat (THREATI) Bivarlate: -N.S., direction suggeats weak gupport of hypothesis G Hypothes1s G supported:

By Age: 01d*

By Bmiloyment: Employed***

By Income: Lowk*

By Or1gin: Rural/Small Town***

Hypothesis G rejected:

By Origin: Urban***

Hypothesis H: Non-swokers are less likely to percelve heart attack/diseage as a personsl threst now or in the future.

IV. Heart Attack/Disease as a Personal Threat (THREAT2)

B1var1ate: -.04 , strong support of hypothesis $\mathrm{H}$

Hypothesis B supported:

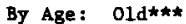

By Education: < H.S.**

By Euployment: "Unemployed"*

By Income: Lowtt

By NCh1ld: 3+ childrea living in home*

By Or1gin: Rural/Small Townk

By Race: White*

Hypothesis H refected:

No significant relationships

Hypothesis I: Non-smokera are more likely to clte a 'nagging cough' as one of the seven signs of cancer.

V. 'Nagging Cough' as Warning S1gn of Cancer (CANCER7)

BIvar1ate: H.S., d1rection suggestg weak support of hypothesis I

Hypothesis I suppored:

By Age: 01d**

By Education: > H.S.*

By Race: Black*

Hypothesis I rejected:

No significant relationships 
Table A2 (continued). Smoking Behavior (SMOKE2A)

Hypothesis J: Non-smokers are more likely to correctly name more of the seven warning signs of cancer.

VI. Seven Warning Signs of Cancer (CANCER8)

Hypothesis J supported:

Bfvarlate: +.08 , moderate support of hypothesis $\mathrm{J}$

By Age: Old $\star \star$

By Education: > H.S.**

By Income: Low*

By NCh1ld: 3+ children living in home*

By Origin: Rural/Small rownk*

By Race: Black kt

Hypothesis $\mathrm{J}$ rejected:

No significant relationshipg

Hypothes is $\mathrm{R}$. Non-smokers are more likely to cite 'not smoking' as a way to reduce chances of heart attack/d1sease.

VII. Heart Problems and Smoking

(HEART3)

Blvarlate: -.000 , strong rejection of hypothesis $\mathrm{K}$

Hypothesis $\mathrm{K}$ supported:

No significant relationships

Hypothesis $\mathrm{X}$ rejected:

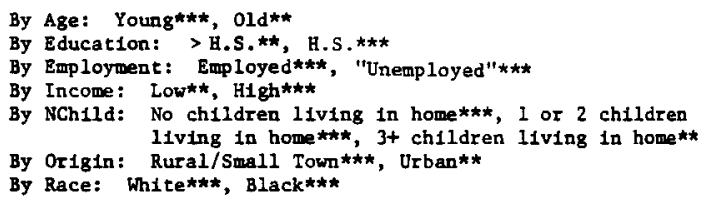

$\mathrm{C}$

$\star . .10>p>.05$, tau B/tau C

$\star *=.05 \rightarrow \mathrm{P}>.01$, tau B/tau C

$\star \star * * .01>p$, tau $B /$ tau $C$ 
Exercise (EXrRC2)

Hypothesis L: People tho exercise regularly are more likely to feel that exercise is important for maincaining good health.

I. Atricude coward Exercise (EXERC7) Hypochesis L supported: Bivariace: +.002 , strong support of hypothesis $L$

\section{..}

Hypothesis L rejected:

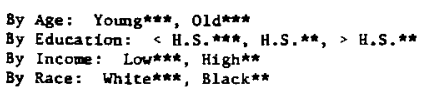

No significant relationships

Hypothesis $M$ : People who exercige regularly are more likely to assess their own personal health
as being better than relevant others.

II. Personal Health Compared to Others (PHEALTH) Bivartate: +.005, strong support of hypothesis $M$

Hypothesis M supported:

By Age: Old**

By Education: \& H.S. ${ }^{\star \star \star}$

By Income: Lort

By Race: White*k, Black*t

Hypothesis M rejected:

No significant relationships

Hypochesis N: People tho exerc1se regularly are less likely to report high levels of cension.

IIt. Level of Daily Tension (IENSE1) Bivartate: -.001, strong support of hypothesis $\mathrm{N}$

Hypothesis i supported:

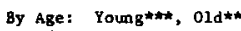

By Educat1 on: \& B.S.**, H.S.***

By Incowe: Lout**

By Race: White*t*, Black»

Hypothesis $\mathrm{N}$ rejected:

No significant relationships

Hypothesis 0: People who exercise regularly are less likely to percelve beart attack/disease as a personal threat oow or in the future.

IV. Hearc Atrack/Disease as a Personal Threat (THREAT2)

Blvariace: + N.S.,direction suggests weak rejection of hypochesis 0

Hypothesis o supporced:

No significant relationships

Hypothesis o rejected:

By Origin: Urban $\star *$

Hypothesis P: People who exerclse regularly are less likely to percelve hypertension as a personal chreat now or in the fucure.

V. Hypertension as a Personal

Threat (THREAT3)

Bivariace: + i.s., direction suggests weak rejection of hypothesis $P$

Hypothesis $P$ supported:

Mo significant relationships

Hypothesis $P$ rejected:

By Age: Young**

By Income: High $\star \star \star$

By NChild: 1 or 2 children living in home**

Hypothesis Q: People who exercise regularly are more likely to cite 'proper exercise' as a way to reduce their chances of heart atcack/disease.

VI. Heare Problen of Exercise (HEARTI)

Bivariate: + N.S., direction suggests weak support of hypothesis $Q$

Hyporhesis Q supported:

By Age: Young **

By Employment: Employed

By Income: Low

By Origin: Urban***

Hypothes1s Q rejected:

No significant relac1onships

*. $.10 \geqslant p>.05$, tau B/tau C 
Seat Belt Use (BELTS1)

Hypothesis R: People who routinely use seat belts are more likely to assess their own health as being better than relevant others.

I. Personal Heatth Compared to Others (PHEALTH)

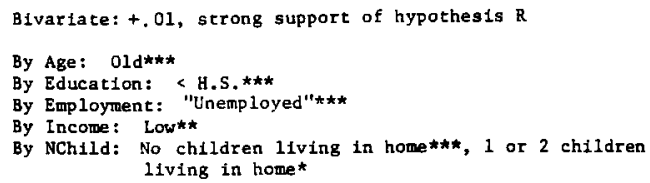

Hypothesis $R$ refected:

No significant relationships

Hypothesis S: People who routinely use seat belts are less likely to report high levels of tension.

II . Leve1 of Daily Tenston (TENSE1)

Bivariaze: -.01, strong support of hypothesis $\mathrm{S}$

Hypothesis S supported:

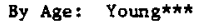

By Education: < H.S.*, H.S.**

By Employment: Employed**, "Unemployed"**

By Income: Hight*

By NChild: No children living in home*t, 3+ children living in home***

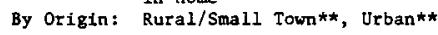

Hypothesis S rejected:

No significant relationships

Hypothesis T: People who routinely use seat belts are more likely to know the four major food groups.

III. Basic Four Food Groups (FooDs)

Bivariate: +.02 , strong support of hypothesis $\mathrm{T}$

Bypothesis $T$ supported:

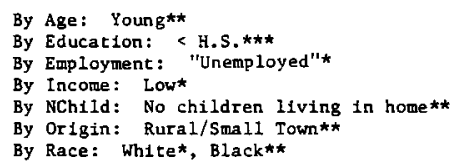

Hypothesis T rejected:

No significant relationships

Hypothesis U: People who roucinely use seat belts are more likely to correctly name more of the seven warning signs of cancer.

IV. Seven Warning Signs of Cancer (CANCER8)

Bivariate: +.10 , direction suggests weak support of hypothesis U

Hypothesis U supported:

By Origin: Rural/small Town*

By Race: White**

Hypothesis it rejected:

No significant relationships

Hypothesis V: People who routinely use seat belts are more likely to cite 'proper exercise' as a way to reduce their chances of heart attack/disease.

V. Heart Problems \& Exercise (HEART1

Bivariate: +.07 , moderate support of hypothesis $\mathrm{V}$

Hypochesis $V$ supported:

By Income: Low*

By NChild: 1 or 2 children living in home***

By Origin: Rural*

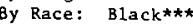

Hypothesis $\mathrm{V}$ rejected:

No significant relationships

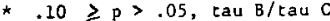

$\star \quad n e \geqslant 0>01$. tau B/tau $C$ 